\title{
Working Hazards and Health Problems among Rubber Farmers in Thailand
}

\section{Pimpisa SAKSORNGMUANG ${ }^{1}$, Orawan KAEWBOONCHOO ${ }^{1, *}$, Ratchneewan ROSS ${ }^{2}$ and Plernpit BOONYAMALIK ${ }^{1}$}

\author{
${ }^{I}$ Department of Public Health Nursing, Faculty of Public Health, Mahidol University, \\ Bangkok 10400, Thailand \\ ${ }^{2}$ Family and Community Department, School of Nursing, University of North Carolina at Greensboro, \\ North Carolina, United States
}

("Corresponding author's email: orawan.kae@mahidol.ac.th)

Received: 26 September 2018, Revised: 25 June 2019, Accepted: 18 July 2019

\begin{abstract}
This study aimed to investigate the working hazards and health problems among rubber farmers in the southern part of Thailand. A cross-sectional survey questionnaire was employed to identify the workers' working hazards and health problems, workers' postures, and the measurement of the intensity of light, lung function, and eye vision. Results indicated that $45.5 \%$ of the rubber farmers were exposed to a chemical substance, $87 \%$ were exposed to a scorpion, and $27.6 \%$ had a high job strain. Furthermore, $43.8 \%$ of the rubber farmers had a high ergonomic risk when collecting the rubber latex. However, the intensity of the headlamp had met the standard. Findings also revealed some common health problems among rubber farmers. These were musculoskeletal disorders $(87.7 \%)$, depression symptoms $(15.7 \%)$, and hand eczema $(8.9 \%)$. Additionally, nearly half of the Thai rubber farmers had an accident at work (45.1\%, while $22 \%$ reported to have bitten by a poisonous animal. Lastly, $78.4 \%$ of the rubber farmers had a low level of visual requirement and half of them had an abnormal lung function (57.2\%). These findings suggest a need for work process modifications to prevent health hazard in Thai rubber farmers.
\end{abstract}

Keywords: Rubber farmers, working hazards, work environment, health problem

\section{Introduction}

Rubber farmers are agricultural workers who play an essential role in the Thai economy and labor market. They are considered as informal sector-workers as they have a low job security, low income, no access to a range of social benefits, and fewer possibilities to participate in formal education and training programs [1]. In Thailand, the National Statistical Office Report (2012) specified that the most common unsafe work environments involve the presence of hazardous chemicals, heavy machinery, and tools which are used by informal sector workers [2], in which rubber farmers are of no exemption.

Admittedly, rubber farming is significant among commercial crops in the south of Thailand. However, rubber farmers have experienced many hazardous exposures at work. They have faced physical hazards including inadequate light when tapping rubber trees at night. Such an inadequate light can cause visual strain and discomfort [3]. They are also prone to chemical contamination such as ammonia, sodium sulfite, formic acid, acetic acid, and herbicides [4]. These chemicals are harmful to workers' health, specifically to their skin and respiratory function [5,6]. In addition, several biological hazards such as vicious animal and mosquitoes are usually found $[3,7,8]$ in the humid areas of rubber plantations. With regard to psychosocial hazards, rubber farmers may also experience anxiety, distress, or stress due to their working conditions. In other words, competition for work time per day, high job demand, characteristics 
http://wjst.wu.ac.th

of working hazards, and fluctuations of rubber prices in news broadcasts affect rubber farmers' health $[4,9]$.

Rubber farming is also a physically demanding occupation. In fact, most rubber farmers are also exposed to ergonomic hazards since their job entails repetitive body movements with the elbow, shoulders, wrist, neck, back, waist, and knees, as well as substantial lifting, walking and the use of manual equipment that affects musculoskeletal health [7,10,11]. Moreover, critical injuries or accidents at work may occur during the rubber working process. For example, using working tools, such as a tapping knife, can cause cutting wounds when rubber farmers whetted the taping knife or tapped a rubber tree. Small iron gutters used to make a track for the latex to drip into the latex cup may also cause accidents or injury to rubber farmers. Lastly, hands and fingers are frequently cut with the tapping knife or small iron gutter $[3,8]$.

Generally, the hazards in the rubber farmer's working process can adversely affect their health either acute or chronic. This condition, either injury and illness, can lead to enormous costs. However, the incidence and the prevalence of occupational diseases or work-related diseases among rubber farmers are underreported [12]. Thus, rubber farmers entail the plan of screening, prevention, surveillance, and health care services. The information about potential working hazards and rubber farmers' health problems will be used to propose projects or policies with regard to their occupational health. Even though several Thai studies were conducted relating to rubber farmer's heath condition, only a few studies have focused on physical, biological, and psychological factors that could potentially affect their health. Therefore, this study aims to examine the working hazards and health problems in Thai rubber farming as well as to determine the relationship between working hazards and health problems among rubber farmers in Thailand.

\section{Materials and methods}

\section{Methods}

A cross-sectional study was conducted from October 2014 to February 2015. The analytical study used randomly selected method and recruited a total of 370 rubber farmers. The sample size was calculated by the proportion of the population at $95 \%$ CI. The proportion was based on the recent study which found that musculoskeletal disorder was 65.1. This was the highest prevalence of occupational diseases and injury in rubber farmers with the level of precision (d) at 0.05 when applied [11]. The data were collected by the researcher and two research assistants. Therefore, the respone rate was $100 \%$.

Multi-stage sampling was used to randomly select 2 provinces from the 14 comprising the southern part of Thailand. Two districts were randomly selected from each province and 2 sub-districts were randomly selected from each district. Finally, eight sub-districts were recruited.

All randomly selected rubber farmers aged between 18 and 60, with work experiences in a rubber farm for at least six months. They were still working in a rubber farm when they were invited to participate via mail.

\section{Instruments}

\section{Questionnaires}

\section{1) Personal characteristics}

Personal characteristics consisted of sex, age, education level, income, underlying disease or present illness, smoking behavior, alcohol consumption, and physical exercise. Working conditions also included the duration of work as rubber farmers, tasks in the rubber farm, and working hour per day and week.

\section{2) Chemical and biological hazards}

Chemical hazards and biological hazards assessed the type, concentration or the number of the hazards, and frequency of exposure. The concentration of the chemical solution used a five-point scale ranging from 1 to $5(1=$ less than $10 \%$ of the chemical when diluting with water, $2=10-30 \%$ of the chemical when diluting with water, $3=31-60 \%$ of the chemical when diluting with water, $4=61-90$ $\%$ of the chemical when diluting with water, and $5=$ grater than $90 \%$ of the chemical when diluting with 
http://wjst.wu.ac.th

water). The frequency of exposure used a five-point scale ranging from 1 to 5 ( 1 = once a year, $2=2-3$ times per year, $3=2-3$ times per month, $4=2-3$ times per week, and $5=$ more than 5 times per week). To evaluate the chemical hazards, frequency score was multiplied by concentration score. The final scores were considered as the likelihood of chemical exposure that ranged from 1 to $5(1=$ no exposure: 1 - 5 scores, 2 = mild exposure: $6-8$ scores, 3 = moderate exposure: 9 - 15 scores, $4=$ high exposure: 16 - 20 scores, and $5=$ extremely high exposure: $21-25$ scores). This likelihood of chemical exposure was used to find a risk score result. The likelihood scores were multiplied by a consequence of chemical exposure for health score. The consequences of chemical exposure for health were given the score by the researcher using a five-point scale ranging from 1 to $5(1=$ no impact for health, $2=$ low impact for health or discomfort; no medical treatment, 3 = moderate impact for health; requires medical treatment, $4=$ high impact for health; requires hospital admission, and $5=$ death or disability). The risk score was then divided into three risk levels (low, moderate, and high).

Consistent with the biological hazard, the number of poisonous animals used a five-point scale ranging from 1 to $5(1=$ less, $2=$ few, $3=$ moderate, $4=$ much, and $5=$ very much). The frequency of seeing poisonous animals used a five-point scale ranging from 1 to $5(1=$ rarely, $2=$ occasional, $3=$ sometimes, $4=$ often, and 5 = always meet while working). By multiplying the score between the frequency and the number of poisonous animals that found per time, the final scores were considered as the likelihood of exposure. The likelihood of exposure scores ranged from 1 to 5 ( 1 = no exposure: 1 - 5 scores, 2 = mild exposure: 6 - 8 scores, $3=$ moderate exposure: 9 - 15 scores, 4 = high exposure: 16 - 20 scores, and $5=$ extremely high exposure: 21 - 25 scores). A risk score result was calculated by the likelihood of biological exposure multiplied by a consequence of biological exposure for health score. The consequence of biological exposure for health used a five-point scale ranging from 1 to 5 ( $1=$ no impact for health, 2 = low impact for health or discomfort; no medical treatment, 3 = moderate impact for health; requires medical treatment, $4=$ high impact for health; requires hospital admission, and $5=$ death or disability). The risk score was divided into three risk levels: low, moderate, and high.

\section{3) Psychosocial hazards}

The 22-item Thai version of the job content questionnaire was used to assess the psychosocial hazards. [13] The survey consists of five items on job demands, nine items on job control, and eight items on social support. Each item used a four-point Likert scale that ranged from 1 to 4 ( $1=$ totally disagree, 2 = disagree, 3 = agree 4 = totally agree). A sum of weighted item scores on job demands and job control was calculated for the job strain and was divided into four categories (high-strain, low strain, active, and passive). Low strain, active, and passive were then grouped into non-high strain. While social support was reported separately and divided into two groups (coworker support and supervisor support).

\section{4) Depression symptoms}

Depressive symptoms were measured using the Thai version of the Center for Epidemiologic Studies Depression Scale (CES-D) [14]. It comprises of 20 items. Each item scored on a four-point Likert scale ranging from 0 to $3(0=$ rarely or none of the time: less than one day per week, $1=$ some or a little of the time: 1 - 2 days per week, 2 = occasionally or a moderate amount of time: 3 - 4 days per week, $3=$ most or all of the time: 5 - 7 days per week). The interpretation of the CES-D score is as follows; 0 - 15: normal, 16 - 22: mild depression, and 23 - 60: severe depression.

\section{5) Musculoskeletal disorders}

Musculoskeletal disorders questionnaire contains a body map to indicate nine symptom sites, which are the illustrated neck, shoulders, upper back, elbows, low back, wrist/hands, hips/thighs, knees, and ankles/feet. The survey questions about musculoskeletal trouble referred to the last 12 months and the previous seven days.

\section{6) Skin disorders}

Occupational skin disorders were measured using the Nordic Occupational Skin Questionnaire (NOSQ-2002 short version) [15]. The NOSQ-2002 questionnaire consists of thirteen questions grouped 
http://wjst.wu.ac.th

into four dimensions: employment history and personal data, history of allergy symptoms, eczema of the hands and forearms, and trigger factors. The NOSQ-2002 questionnaire was compiled in English with scientific medical language. Translation into Thai and back-translation were employed.

\section{7) Poisonous animal bite} bitten.

The poisonous animal bite survey comprised of the type of animal and part of the body that was

\section{8) Occupational accident and injury}

Occupational accident and injury questionnaire entailed the parts of body injured and the type of the accident.

All questionnaires were tested for reliability and validity in a pilot study. The result showed good validity and reliability which ranged between .64 and 1 .

\section{A pen and paper-based observation}

Rapid Upper Limb Assessment (RULA) was used to assess the level of ergonomic risk by considering the posture of rubber farmers while they were working. The RULA score indicated an ergonomic risk in four levels (negligible, low, moderate, high risk). Inter-rater reliability among the researcher and two research assistants was 1 .

\section{Measurement devices}

Measurement devices used 1) lux meter (light meter model LX70) to measure an intensity of light, 2) spirometer (Spirolab II) to measure lung function, and 3) vision tester (OPTEC2500) to measure eye vision. The measurement devices were calibrated for accuracy.

\section{Statistical Analyses}

The descriptive statistical analysis was used to report the response rate of closed-ended questions. Quantitative variables were expressed as the mean, and standard deviation or as percentages. Chi-square test was used to assess the association between occupational hazards and health problems. Multiple logistic regression was used to determine the factors related to health problems. Data were analyzed using SPSS Version 22 (IBM Corp.). Statistical significance was set at $\mathrm{p}<.05$.

\section{Ethical approval}

The study was approved by the ethical review committee for human research of the Faculty of Public Health at Mahidol University (No. MUPH 2014-172 and Protocol No. 117/2557). Anonymity was maintained to protect the participants' identity and confidentiality. The participation in this study was voluntary.

\section{Results and discussion}

\section{Personal characteristics}

The 370 rubber farmers were $76.8 \%$ female. Their average age was 47 (SD 9.1) years. Most of them were married (82.4\%)and more than half had completed only primary school $(62 \%)$. Likewise, half of them reported having insufficient income and about one-quarter of the rubber farmers had a chronic illness $(23.8 \%)$. Although sixteen percent of the rubber farmers had smoking and alcohol consumption habits, only seven percent of them exercised regularly (Table 1). 
http://wjst.wu.ac.th

Table 1 Characteristic of subjects

\begin{tabular}{lc}
\hline \multicolumn{1}{c}{ Demographic Data $(\mathbf{n}=\mathbf{3 7 0})$} & Number $\mathbf{( \% )}$ \\
\hline Sex & \\
Male & $86(23.2)$ \\
Female & $284(76.8)$ \\
Age (years) & $83(22.4)$ \\
18-40 & $287(77.6)$ \\
40-60 & \\
Married status & $24(6.5)$ \\
Single & $305(82.4)$ \\
Married & $41(11.1)$ \\
Windowed/ Divorced & $16(4.3)$ \\
Highest Education level & $228(61.6)$ \\
No education & $45(12.2)$ \\
Primary school & $81(21.9)$ \\
Secondary school & \\
High school and higher & $184(49.7)$ \\
Adequacy of income & $151(40.8)$ \\
Lacking & $35(9.5)$ \\
Enough income but no saving & \\
Enough income and saving & $5(1.4)$ \\
Diseases & $277(74.9)$ \\
Don't know (never check) & $88(23.8)$ \\
No & \\
Yes & $311(84.1)$ \\
Smoking & $18(4.9)$ \\
No & $41(11.1)$ \\
Yes and used to smoke & \\
Yes and current smoking & $308(83.2)$ \\
Alcohol consumed & $56(15.1)$ \\
No & $6(1.6)$ \\
Yes, sometimes & \\
Yes, often & $161(43.5)$ \\
Exercise & $183(49.5)$ \\
No & $26(7.0)$ \\
Yes, sometimes & \\
Yes, often & \\
& \\
\hline & \\
\hline
\end{tabular}

\section{Working conditions}

The working experience in rubber farming ranged from 1 to 50 years, with an average working experience of 24.4 years (SD 12.6). Most of them tapped rubber trees and kept rubber latex as usual activity. Only two percent of them made rubber sheets. The average working hours per day was six hours (SD 1.5). The majority of rubber farmers worked five days per week (SD 0.9).

\section{Working hazards}

Chemical hazards

Forty-six percent of the respondents used chemical substance in their work. Thirty-seven percent of them used liquid ammonia as latex anti-coagulant, while only two percent of them used acid as a latex 
http://wjst.wu.ac.th

coagulant when making rubber sheets. Seventeen percent used herbicides. Most of the chemical users had a low-risk level (Table 2).

\section{Biological hazards}

All rubber farmers experienced mosquitoes when they worked. The majority of the rubber farmers found scorpions or centipedes $(86.8 \%)$, more than half of them found snakes $(69.2 \%)$, and some rubber farmers found bees or wasps or hornets in their areas (7.3\%). According to biological hazards risk, most rubber farmers $(94.9 \%)$ who faced with mosquitoes were at a moderate risk. $82.9 \%$ who found scorpions or centipedes were at a low risk. More than half of them $(64.6 \%)$ who found snakes were at a low risk. While $7.3 \%$ of rubber farmers who reported to have faced with bees or wasps or hornets were at low risk (Table 2).

\section{Psychosocial hazards}

Twenty-eight percent of the rubber farmers was found to be in a high job strain group, while $72.4 \%$ was found in a non-high job strain group. The non-high job strain group was divided into three groups (active, low-strain, and passive). Thirty-four percent of the rubber farmers were in an active group, and 19 $\%$ were in each low-strain group and passive group.

According to the social support, $85.9 \%$ received support from their workplace, $87.8 \%$ received support from supervisors, and $91.4 \%$ received support from coworkers (Table 2).

\section{Ergonomic risk}

For tapping rubber trees postures, nearly half of them had a moderate risk (48.6\%), and twelve percent of them had a high risk. While the rubber farmers were collecting rubber latex, half of them had a moderate risk $(54.5 \%$ ), and forty-four percent of them had a high risk (Table 2).

\section{Lighting at work}

The rubber farmers used headlamps for work at night time. The intensity of light at a task position was in a range between 208 - 1876 lux, with an average of 805 lux (SD 209) that met the standard of the intensity of light by the Ministry of Labor and Social Welfare, Thailand (Table 2).

Table 2 Working hazards

\begin{tabular}{cl}
\hline Working Hazards & Number (\%) \\
\hline $\begin{array}{c}\text { Chemical hazards exposure }(\mathrm{n}=370) \\
\text { No }\end{array}$ Yes $\quad$ Liquid ammonia & $202(54.5)$ \\
$\quad$ Low risk & $168(45.5)$ \\
Moderate risk & $135(36.5)$ \\
Acid $\quad 110(29.7)$ \\
Low risk & $25(6.8)$ \\
Herbicide & $8(2.2)$ \\
Low risk & $8(2.2)$ \\
Moderate risk & $64(17.3)$ \\
Biological hazards exposure (n=370) & $62(16.8)$ \\
Mosquitoes & $2(0.5)$ \\
Low risk & $370(100.0)$ \\
Moderate risk & $19(5.1)$ \\
Scorpions or centipedes & $351(94.9)$ \\
Low risk & $321(86.8)$ \\
& $306(82.9)$
\end{tabular}




\begin{tabular}{cl}
\hline Working Hazards & Number (\%) \\
\hline Moderate risk & $15(4.1)$ \\
Snake & $256(69.2)$ \\
Low risk & $239(64.6)$ \\
Moderate risk & $17(4.6)$ \\
Bee or wasp or hornet & $27(7.3)$ \\
Low risk & $27(7.3)$ \\
Job strain and support $(\mathrm{n}=370)$ & $102(27.6)$ \\
High strain & $268(72.4)$ \\
Non-high strain & $125(33.8)$ \\
Active & $71(19.2)$ \\
Low strain & $72(19.2)$ \\
Passive & $318(85.9)$ \\
Workplace social support & $325(87.8)$ \\
Supervisors support & $338(91.4)$ \\
Coworkers support & \\
Ergonomic risk & \\
Tapping rubber tree $(\mathrm{n}=364)$ & $142(39.0)$ \\
Low risk & $177(48.6)$ \\
Moderate risk & $45(12.4)$ \\
High risk & $6(1.7)$ \\
Collecting rubber latex $(\mathrm{n}=363)$ & $198(54.5)$ \\
Low risk & $159(43.8)$ \\
Moderate risk & $137(37.6)$ \\
High risk & $120(33.0)$ \\
200-599 & $61(16.8)$ \\
600-999 & $46(12.6)$ \\
1000-1399 & \\
$\geq 1400$ & \\
\hline
\end{tabular}

\section{Rubber farmer's health}

Depression Symptoms

Sixteen percent of the participants had depression symptoms (15.7\%). They also had mild depression (9.5\%) and severe depression (6.2\%) (Table 3).

\section{Musculoskeletal disorders (MSDs)}

The prevalence rate of MSDs for seven days period was forty-eight percent (47.6\%), and the twelve months was eighty-eight percent $(87.7 \%)$. The lower back was the most commonly complained disorder for 12 months $(36.8 \%)$. Twenty-nine percent of the rubber farmers had shoulder and knee complaint $(28.9 \%)$. Nineteen percent of them had hip or thigh disorders $(18.9 \%)$. Eighteen percent of them had ankle or foot disorder (17.8\%) (Table 3).

\section{Skin disorders}

Nine percent of the rubber farmers had eczema on their hands. Eight percent of them had wrist or forearm eczema. More than half of the rubber farmers who had eczema did not know that materials, chemicals, or something else in their work made their eczema worse than before. Only nine percent of them knew those materials and chemicals in their work that could make their hand and wrist, or forearms eczema became worse (Table 3). 
http://wjst.wu.ac.th

\section{Poisonous animal bite}

Twenty-two percent of the rubber farmers had been bitten by poisonous animals at work in the last 12 months. More than half of them were bitten by scorpions $(63.4 \%)$. Others were bitten by bees or wasps $(18.3 \%)$, centipedes $(11.0 \%)$ and snakes $(7.3 \%)$. Hand and fingers were commonly bitten $(79.3$ \%) (Table 3).

\section{Occupational accident and injury}

Nearly half of the rubber farmers experienced an accident at work in the last 12 months (45.1\%). Hands or fingers were frequently injured $(69.5 \%$ ) while $23.4 \%$ of them had injuries at legs. More than half of them experienced cutting wound from the tapping knife or latex gutter $(65.9 \%)$, while one-fourth of them experienced slipping at work $(26.7 \%)$ (Table 3).

\section{Eye vision}

According to a job standard for unskilled labor, most of the rubber farmers had failed the visual requirement (78.4\%) (Table 3).

\section{Lung Function}

Fifty-seven percent of the participants had abnormal lung function (57.2\%). $40.9 \%$ of them had a mild restriction, $14.4 \%$ had moderate restrictions, and $1.6 \%$ had severe restrictions (Table 3 ).

Table 3 Rubber farmer's health

\begin{tabular}{|c|c|}
\hline Rubber farmer's health & Number $(\%)$ \\
\hline \multicolumn{2}{|l|}{ Depression Symptoms $(\mathrm{n}=370)$} \\
\hline Normal & $312(84.3)$ \\
\hline Depression & $58(15.7)$ \\
\hline mild & $35(9.5)$ \\
\hline Severe & $23(6.2)$ \\
\hline \multicolumn{2}{|c|}{ Musculoskeletal Disorders (MSDs) $(\mathrm{n}=370)$} \\
\hline 7 days & $176(47.6)$ \\
\hline 12 months & $325(87.7)$ \\
\hline Neck & $52(14.4)$ \\
\hline Shoulder & $107(28.9)$ \\
\hline Elbow & $51(13.8)$ \\
\hline Wrist/hand & $57(15.4)$ \\
\hline Upper back & $26(7.0)$ \\
\hline Lower back & $136(36.8)$ \\
\hline Hip/thigh & $70(18.9)$ \\
\hline Knee & $107(28.9)$ \\
\hline Ankle/feet & $66(17.8)$ \\
\hline \multicolumn{2}{|l|}{ Skin eczema $(n=370)$} \\
\hline Hand eczema & $33(8.9)$ \\
\hline \multicolumn{2}{|c|}{ Materials, chemicals or anything else from work makes eczema worse } \\
\hline No & $13(39.4)$ \\
\hline Yes & $3(9.1)$ \\
\hline Don’t know & $17(51.5)$ \\
\hline Wrists/forearms eczema & $31(8.4)$ \\
\hline \multicolumn{2}{|c|}{ Materials, chemicals or anything else from work makes eczema worse } \\
\hline No & $11(35.5)$ \\
\hline Yes & $3(9.7)$ \\
\hline
\end{tabular}




\begin{tabular}{|c|c|}
\hline Rubber farmer's health & Number (\%) \\
\hline Don't know & $17(54.8)$ \\
\hline Poisonous animal bite $(\mathrm{n}=370)$ & $82(22.2)$ \\
\hline Snake & $6(7.3)$ \\
\hline Centipede & $9(11.0)$ \\
\hline Scorpion & $52(63.4)$ \\
\hline Bee/wasp/ hornet & $15(18.3)$ \\
\hline \multicolumn{2}{|l|}{ Part of body was bitten } \\
\hline Head/face & $5(6.1)$ \\
\hline Hand/finger & $65(79.3)$ \\
\hline Leg/foot & $12(14.6)$ \\
\hline Occupational accident and injury $(\mathrm{n}=370)$ & $167(45.1)$ \\
\hline Head/face & $3(1.8)$ \\
\hline Body & $3(1.8)$ \\
\hline Hand/finger & $116(69.5)$ \\
\hline Leg & $39(23.4)$ \\
\hline Foot & $6(3.6)$ \\
\hline \multicolumn{2}{|l|}{ Type of accident } \\
\hline Slip & $44(26.7)$ \\
\hline Cut injuries & $110(65.9)$ \\
\hline Contact the object & $3(1.8)$ \\
\hline Vehicle accident & $10(6.0)$ \\
\hline \multicolumn{2}{|c|}{ Visual requirements for unskilled labor $(\mathrm{n}=370)$} \\
\hline Pass & $80(21.6)$ \\
\hline Fail & $290(78.4)$ \\
\hline \multicolumn{2}{|l|}{ Lung Function $(\mathrm{n}=367)$} \\
\hline Normal & $157(42.8)$ \\
\hline Abnormal & $210(57.2)$ \\
\hline Mild restriction & $150(40.9)$ \\
\hline Moderate restriction & $53(14.4)$ \\
\hline Severe restriction & $6(1.6)$ \\
\hline Mixed type & $1(0.3)$ \\
\hline
\end{tabular}

\section{Relationship between health problems and working hazards}

\section{Low back disorder}

Table 4 indicates the items that were significantly associated with low back disorder among rubber farmers. The ergonomic risk when the rubber farmers tapped the rubber tree was significantly related to low back disorders. Moreover, the trunk position scores when rubber farmers collected the rubber latex and the total scores of the neck, trunk and leg when they tapped the rubber tree were significantly related to low back disorders. 
http://wjst.wu.ac.th

Table 4 Items showing significant associated with the low back disorder and related factors

\begin{tabular}{|c|c|c|c|c|c|}
\hline \multirow{2}{*}{ Risk Factors } & \multirow{2}{*}{ Number (\%) } & \multirow{2}{*}{$\chi^{2}$} & \multirow{2}{*}{ Crude OR } & \multicolumn{2}{|c|}{$95 \%$ CI for OR } \\
\hline & & & & Lower & Upper \\
\hline \multicolumn{6}{|c|}{ Ergonomic risk: tapping a rubber tree $(n=364)$} \\
\hline Low & $42(29.6)$ & $7.68 * *$ & 1 & & \\
\hline Moderate & $70(39.5)$ & & 1.56 & 0.97 & 2.49 \\
\hline High & $23(51.1)$ & & $2.49 *$ & 1.25 & 4.95 \\
\hline \multicolumn{6}{|c|}{ Trunk position score $(C 10)$ : collecting rubber latex $(n=363)$} \\
\hline $1-2$ score & $58(28.4)$ & $11.84 *$ & 1 & & \\
\hline 3-4 score & $73(45.9)$ & & $2.17 *$ & 1.38 & 3.30 \\
\hline \multicolumn{6}{|c|}{ Total score of neck trunk leg (T15): tapping rubber tree $(n=364)$} \\
\hline 1-4 score & $38(28.9)$ & $7.79 *$ & 1 & & \\
\hline $5-8$ score & $97(42.5)$ & & $1.91 *$ & 1.21 & 3.02 \\
\hline
\end{tabular}

Abbreviation: $\mathrm{OR}=$ odds ratio, $\mathrm{CI}=$ confidence interval

$* \mathrm{p}<0.01, * * \mathrm{p}<0.05$

Table 5 shows the multiple logistic regression analysis for factors related to low back disorder. The ergonomic high risk (OR 2.47), trunk position scores (3 - 4 score) (OR 1.97), the total score of neck trunk leg $(5-8$ score) and the score when the rubber farmers tapped rubber latex (OR 1.89) were more likely to reported by rubber farmers as factors for low back disorder compared with the rubber farmers who did not have these factors. Rubber farmers who had the trunk position scores (3-4 score) when they collected the rubber latex was likely to have low back disorder compared with the rubber farmers who had trunk position scores (1 - 2 score) (OR 2.08).

Table 5 Multiple logistic regression analysis for factors related to low back disorder

\begin{tabular}{|c|c|c|c|c|c|c|}
\hline & \multirow{2}{*}{ B } & \multirow{2}{*}{ S.E. } & \multirow{2}{*}{$\begin{array}{c}\text { Adjusted } \\
\text { OR }\end{array}$} & \multicolumn{2}{|c|}{$95 \%$ CI for OR } & \multirow{2}{*}{ p-value } \\
\hline & & & & Lower & Upper & \\
\hline \multicolumn{7}{|c|}{ Ergonomic risk: tapping a rubber tree } \\
\hline Low & & & 1 & & & \\
\hline Moderate(1) & .447 & .242 & 1.564 & .974 & 2.512 & .064 \\
\hline $\operatorname{High}(2)$ & .904 & .356 & $2.469 * *$ & 1.228 & 4.963 & .011 \\
\hline \multicolumn{7}{|c|}{ Trunk position score (T10): tapping a rubber tree } \\
\hline $1-2$ score & & & 1 & & & \\
\hline $3-4$ score $(1)$ & .678 & .333 & $1.971 * *$ & 1.026 & 3.784 & .042 \\
\hline \multicolumn{7}{|c|}{ Total score of neck trunk leg (T15): tapping a rubber tree } \\
\hline $1-4$ score & & & 1 & & & \\
\hline $5-8$ score $(1)$ & .637 & .235 & $1.891^{*}$ & 1.193 & 2.999 & .007 \\
\hline \multicolumn{7}{|c|}{ Trunk position score $(\mathrm{C} 10)$ : collecting rubber latex } \\
\hline $1-2$ score & & & 1 & & & \\
\hline 3-4 score $(1)$ & .734 & .228 & $2.083^{*}$ & 1.334 & 3.254 & .001 \\
\hline
\end{tabular}

Adjusted for: sex, age, smoking, exercise, body mass index, working hour per week

Abbreviation: $\mathrm{OR}=$ odds ratio, $\mathrm{CI}=$ confidence interval

$* \mathrm{p}<0.01, * * \mathrm{p}<0.05$ 


\section{Shoulder disorders}

Table 6 presents the items that were significantly associated with shoulder disorder among rubber farmers. The exercise, the ergonomic risk, and the shoulder position when the rubber farmers tapped rubber latex were significantly related to shoulder disorder. The load score when the rubber farmers collected rubber latex was significantly associated with shoulder disorder. Depression symptoms were also related to shoulder disorder.

Table 6 Items significantly associated with shoulder disorder and related factors

\begin{tabular}{|c|c|c|c|c|c|}
\hline \multirow{2}{*}{ Risk Factors } & \multirow{2}{*}{ Number (\%) } & \multirow{2}{*}{$\chi^{2}$} & \multirow{2}{*}{ Crude OR } & \multicolumn{2}{|c|}{$95 \%$ CI for OR } \\
\hline & & & & Lower & Upper \\
\hline \multicolumn{6}{|c|}{ Exercise $(n=370)$} \\
\hline No & $35(21.7)$ & \multirow[t]{3}{*}{$7.38^{*}$} & 1 & & \\
\hline Sometime & $62(33.9)$ & & $1.85^{* *}$ & 1.14 & 2.99 \\
\hline Often & $10(38.5)$ & & 2.25 & 0.94 & 5.39 \\
\hline \multicolumn{6}{|c|}{ Ergonomic risk: tapping a rubber tree $(n=364)$} \\
\hline Low & $27(19.0)$ & \multirow[t]{3}{*}{$10.24 *$} & 1 & & \\
\hline Moderate & $59(33.3)$ & & $2.13 *$ & 1.26 & 3.59 \\
\hline High & $17(37.8)$ & & $2.59 * *$ & 1.24 & 5.39 \\
\hline \multicolumn{6}{|c|}{ Shoulder position score (T1): tapping a rubber tree $(n=364)$} \\
\hline $1-3$ score & $67(23.9)$ & \multirow[t]{2}{*}{$11.41 *$} & 1 & & \\
\hline 4-6 score & $36(42.9)$ & & 2.38 & 1.43 & 3.99 \\
\hline \multicolumn{6}{|c|}{ Load score $(C 7)$ : collecting rubber latex $(n=363)$} \\
\hline 0 -1 score & $22(19.3)$ & \multirow[t]{2}{*}{$7.88^{*}$} & 1 & & \\
\hline $2-3$ score & $84(33.7)$ & & 2.13 & 1.25 & 3.63 \\
\hline \multicolumn{6}{|c|}{ Depression symptom $(\mathrm{n}=370)$} \\
\hline No & $77(24.7)$ & \multirow[t]{2}{*}{$17.40^{*}$} & 1 & & \\
\hline Yes & $30(51.7)$ & & 3.27 & 1.84 & 5.82 \\
\hline
\end{tabular}

Abbreviation: $\mathrm{OR}=$ odds ratio, $\mathrm{CI}=$ confidence interval

$* \mathrm{p}<0.01, * * \mathrm{p}<0.05$

Table 7 shows the multiple logistic regression analysis for factors related to shoulder disorder. Rubber farmers who had the ergonomic moderate risk (OR 2.20), ergonomic high risk (2.63), and shoulder position score (4 - 6 score) and the score when the rubber farmers tapped rubber latex (OR 2.44) were more likely to report as shoulder disorder compared with the rubber farmers who had not experienced these factors. Rubber farmers who had the load score (2 - 3 score) when they collected rubber latex (OR 2.14) and the depression symptom (OR 3.40) were also more likely to report shoulder disorder compared with the rubber farmers who did not have these factors. 
http://wjst.wu.ac.th

Table 7 Multiple logistic regression analysis for factors related to shoulder disorder

\begin{tabular}{|c|c|c|c|c|c|c|}
\hline & \multirow{2}{*}{ B } & \multirow{2}{*}{ S.E. } & \multirow{2}{*}{$\begin{array}{c}\text { Adjusted } \\
\text { OR }\end{array}$} & \multicolumn{2}{|c|}{$95 \%$ CI for OR } & \multirow{2}{*}{ p-value } \\
\hline & & & & Lower & Upper & \\
\hline \multicolumn{7}{|c|}{ Ergonomic risk: tapping a rubber tree } \\
\hline Low & & & 1 & & & \\
\hline Moderate(1) & .786 & .271 & $2.195^{*}$ & 1.289 & 3.737 & .004 \\
\hline $\operatorname{High}(2)$ & .965 & .385 & $2.626 * *$ & 1.235 & 5.584 & .012 \\
\hline \multicolumn{7}{|c|}{ Shoulder position score (T1): tapping a rubber tree } \\
\hline $1-3$ score & & & 1 & & & \\
\hline 4-6 score $(1)$ & .891 & .270 & $2.439 *$ & 1.437 & 4.138 & .001 \\
\hline \multicolumn{7}{|c|}{ Load score (C7): collecting rubber latex } \\
\hline $0-1$ score & & & 1 & & & \\
\hline $2-3 \operatorname{score}(1)$ & .759 & .282 & $2.136^{*}$ & 1.230 & 3.709 & .007 \\
\hline \multicolumn{7}{|c|}{ Depression symptom } \\
\hline No & & & 1 & & & \\
\hline Yes(1) & 1.223 & .302 & $3.399 *$ & 1.882 & 6.137 & $<.001$ \\
\hline
\end{tabular}

Adjusted for: sex, age, smoking, exercise, body mass index, working hour per week

Abbreviation: $\mathrm{OR}=$ odds ratio, $\mathrm{CI}=$ confidence interval

$* \mathrm{p}<0.01, * * \mathrm{p}<0.05$

\section{Depression symptoms}

Table 8 shows that marital status, education, and social support were significantly related to depression symptom.

Table 8 Items showing significant associated with depression symptom and related factors

\begin{tabular}{|c|c|c|c|c|c|}
\hline \multirow{2}{*}{ Risk Factors } & \multirow{2}{*}{ Number (\%) } & \multirow{2}{*}{$\chi^{2}$} & \multirow{2}{*}{ Crude OR } & \multicolumn{2}{|c|}{$95 \%$ CI for OR } \\
\hline & & & & Lower & Upper \\
\hline \multicolumn{6}{|l|}{ Married status $(n=370)$} \\
\hline Married & $42(13.8)$ & $4.77 * *$ & 1 & & \\
\hline Single/windowed & $16(24.6)$ & & $2.05 * *$ & 1.07 & 3.92 \\
\hline \multicolumn{6}{|l|}{ Education $(n=370)$} \\
\hline Lower or high school & $53(14.8)$ & $6.34 * *$ & 1 & & \\
\hline Higher high school & $5(41.7)$ & & $4.11 * *$ & 1.26 & 13.43 \\
\hline \multicolumn{6}{|l|}{ Social support $(n=370)$} \\
\hline High & $42(13.2)$ & $10.43^{*}$ & 1 & & \\
\hline Low & $16(30.8)$ & & 2.92 & 1.49 & 5.72 \\
\hline
\end{tabular}

Abbreviation: OR, odds ratio: $\mathrm{CI}$, confidence interval

$* \mathrm{p}<0.01, * * \mathrm{p}<0.05$

This study also found a significant relationship between the poisonous animal bite and biological risk exposures including the moderate risk exposure to snake (OR 5.00, $95 \%$ CI 1.64 - 15.27), and the moderate risk exposure to scorpion or centipede (OR 9.84, $95 \%$ CI 2.33 - 41.56). 
http://wjst.wu.ac.th

\section{Discussion}

This study found that the rubber farmers were harmly exposed to a chemical substance, poisonous animals, and job strain. They also had a high ergonomic risk. In fact, musculoskeletal disorders were the common health problems $(87.7 \%)$ reported among rubber farmers. Additionally, rubber farmers also failed in their visual requirement (78.4\%), had abnormal lung function $(57.2 \%$.), experienced accident at work $(45.1 \%)$, bitten by poisonous animal (22\%), had depressive symptoms $(15.7 \%)$, and had hand eczema $(8.9 \%)$.

The chemicals substance used in the rubber farming were at low risk because the concentrations of the chemical were diluted [16]. Moreover, most of the rubber farmers sold raw rubber latex rather than rubber sheets that can reduce the acid used. A few of the rubber farmers used herbicide in rubber farm. They usually cut the grasses rather than spray the chemicals. However, the prolonged effects of exposure to chemicals were not studied in this group. For this reason, this study identified the skin problems and tested the lung fucntions among rubber farmers. A few rubber farmers who had eczema on their hands and forearms recognized that their eczema worsened when they were in contact with materials, chemicals, or anything else from work. Nearly half of the rubber farmers had abnormal lung function. However, many factors can cause lung functions to become worse. Therefore, future study will need to examine the exposure of chemical used that affects lung functions.

Mosquitoes, snakes, and scorpions were commonly found in the rubber farm. Rubber fields are areas for mosquitoes to thrive because of humidity. It is also a place for stagnant rainwater where cups were colected to be used for the rubber latex. All of the rubber farmers found mosquitoes in their fields. However, statistics on mosquito-borne diseases were not recorded. An Indian study in rubber plantations in Kerala revealed that 12 species of mosquitoes were found to breed in rainwater-filled cups used for collecting rubber latex [17]. Likewise, $69.2 \%$ of the rubber farmers found snakes in their area. In fact, seven of them had snake bites. These findings were congruent to many studies that found a risk of snake bite in rubber tapper $[3,8,18]$.

With regard to psychosocial hazards, the rubber farmer experienced stress in their work, which correspond to the previous study [8]. However, rubber farmers had a high social support from their family members and co-workers. The social support at work was directly related to deep depression [19]. The high number of support was referred to cultural context of the Thai rural family and community.

Most of the rubber farmers had musculoskeletal disorders. In addition, rubber farmers commonly complained about their low back pain and shoulder pain. These health problems were related to the repeat of over-flexion or overextension posture and awkward posture [20]. The previous study found that musculoskeletal disorders were associated with working on a rubber farm $[3,7,8,11,21]$.

Lastly, the intensity level of light met the standard of Minister of Labor and Social Welfare in Thailand. However, most rubber farmers did not pass the vision standard, which was for unskilled labor. This result is related to the age of the rubber farmers [22]. Therefore, their age is related to their working experience in rubber farm that exposes to poor lighting when working at night [3]. Moreover, working at night can cause the accident. Most of the rubber farmers had accidents at night. The cutting wounds from tapping a knife or latex gutter were frequently found $[3,8]$.

\section{Conclusions}

Rubber farmers play an essential role in the Thai economy. However, their working environment poses a threat to their health. The findings of this study on working hazards and health issues among rubber farmers could be used to develop a program in order to reduce their health problem and eliminate the hazards. Occupational health officer should address the health problems among rubber farmers and provide them the support they need. This action could be implemented with a rubber farmer's participation in occupational health programs. 
http://wjst.wu.ac.th

\section{Acknowledgment}

The authors would like to thank the hospital personnel and village health volunteers from Thangiew, Lamo sub-district, Trang province; Thunglan, and Tungtumsao sub-district, Songkhla province, who assisted them in conducting and facilitating this study.

\section{References}

[1] R Hussmanns and F Mehran. Statistical definition of the informal sector - International standards and national practices, 1999. Available at: http://www.gdrc.org/informal/huss0772.pdf, accessed February 2012.

[2] C Kanchanachitra, C Podhisita, K Archavanitkul, U Pattaravanich and C Chamchan. Thaihealth2010: 12 Health Indicators of Thailand's Workforce. Nakorn Pathom: Institute for Population and Social Research, Mahidol University, Thai Health Promotion Foundation, The National Health Commission Office, 2010.

[3] P Maaidee, S Khongthong, O Eiamkham and S Sinlaparatsamee. Health Status Of Rubber Farmer. Nakhon Si Thammarat Provincial Public Health Office, Nakhon Si Thammarat, 2004.

[4] S Thungwa, B Somboonsuk and P Dhumrattana. The impact of socio-economic, working culture in para-rubber plantation on environment, health status and quality of life of para-rubber smallholders, Sadao, Songkhla. Available at: http://www.mcc.cmu.ac.th/Seminar/pdf/989629997.pdf, accessed October 2013.

[5] Brenntag Canada. Material safety data sheet Material safety data sheet; Sodium sulphite, Solid. Available at: http://www.dynamicaqua.com/msds/Sodium Sulphite.pdf, accessed July 2013.

[6] Canadian Centre for Occupational Health \& Safety. Ammonia. Available at: https://www.ccohs.ca/oshanswers/chemicals/chem_profiles/ammonia.html, accessed July 2013.

[7] Y Jantarapimol, C Chanprasit and W Songkhum. Health status and health preventive behaviors among rubber plantation workers. J. Health Sci. 2007; 13, 390-9.

[8] P Boonphadh. 2008, The Perceived Effects of Work on Health of Rubber Farmers in Southern Thailand, Ph.D. Dissertation. Massay University, Palmerston North, New Zealand.

[9] S Leka and A Jain. Health Impact of Psychosocial Hazards at Work: An Overview. Geneva, Switzerland, 2010.

[10] N Bensa-ard. Work condition and musculoskeletal pain among para rubber planters: A case study in Tambon Nakleua, Amphoe Kantang, Changwar Trang, Master's Thesis. Prince of Songkla University, Songkla, Thailand, 2002.

[11] R Plykeaw, C Chanprasit and T Kaewthummanukul. Working posture and musculoskeletal disorders among rubber plantation worke. Nurs. J. 2013; 40, 1-10.

[12] S Siriruttanapruk, K Wada and T Kawakami. Promoting occupational health services for workers in the informal economy through primary care units. Available at: http://www.ilo.org/wcmsp5 /groups/public/@asia/@ro-bangkok/@sro-bangkok/documents/publiccation/wcms_114237.pdf, accessed February 2012.

[13] P Phaktongsuk and N Apakupakul. Psychometric properties of the Thai version of the 22-item and 45-item Karasek job content questionnaire. Int. J. Occup. Med. Environ. Health 2008; 21, 331-44.

[14] R Ross, R Zeller, P Srisaeng, S Yimmee, S Somchid and W Sawatphanit. Depression, stress, emotional support, and self-esteem among baccalaureate nursing students in Thailand. Int. J. Nurs. Educ. Scholarsh 2005; 2, 11-24.

[15] P Susitaival, MA Flyvholm, B Meding, L Kanerva, M Lindberg, Å Svensson and JH Ólafsson. Nordic occupational skin questionnaire (NOSQ-2002): A new tool for surveying occupational skin diseases and exposure. Contact Dermatitis 2003; 49, 70-6.

[16] W Jawjit, P Pavasant and C Kroeze. Evaluating environmental performance of concentrated latex production in Thailand. J. Clean. Prod. 2015; 98, 84-91.

[17] PK Sumodan. Species diversity of mosquito breeding in rubber plantations of Kerala, India. J. Am. Mosq. Control Assoc. 2012; 28, 114-5. 
http://wjst.wu.ac.th

[18] SV Pierini, DA Warrell, A De Paulo and RDG. Theakston. High incidence of bites and stings by snakes and other animals among rubber tappers and amazonian indians of the Juruá Valley, Acre State, Brazil. Toxicon 1966; 34, 225-36.

[19] KO Park, MG Wilson and SL Myung. Effects of social support at work on depression and organizational productivity. Am. J. Health Behav. 2004; 28, 444-55.

[20] BP Bernard. Musculoskeletal disorders and workplace factors: A critical review of epidemiologic evidence for work-related musculoskeletal disorders of the neck, upper extremity, and low back. Available at: https://www.cdc.gov/niosh/docs/97-141/pdfs/97-141.pdf, accessed February 2012.

[21] S Meksawi, B Tangtrakulwanich and V Chongsuvivatwong. Musculoskeletal problems and ergonomic risk assessment in rubber tappers: A community-based study in southern Thailand. Int. J. Ind. Ergon. 2012; 42, 29-135.

[22] SC Smith. Vision and the coming of age. Insight 2015; 40, 5-10. 